\title{
The CoViBE: An Innovating Self-Paced Elearning to Teach Virtually Bench-Top Practice
}

\author{
Aya Abou Hammoud ${ }^{1,2}$, Nestor Pallares-lupon ${ }^{1,3}$, Anthony Bouter ${ }^{1,4} \&$ Corinne Faucheux ${ }^{1,5}$ \\ ${ }^{1}$ Biology Training Unit, University of Bordeaux, Pessac, France \\ ${ }^{2}$ CNRS UMR 5234 Fundamental Microbiology and Pathogenicity, Team Protist Parasite Cytoskeleton, \\ Bordeaux, France \\ ${ }^{3}$ IHU Liryc, Electrophysiology and Heart Modeling Institute; Cardio-Thoracic Research Center of Bordeaux - \\ INSERM U1045, Xavier Arnozan Campus, Pessac, France \\ ${ }^{4}$ Institute of Chemistry and Biology of Membranes and Nano-objects, UMR 5248, CNRS, Pessac, France \\ ${ }^{5}$ Univ. Bordeaux, INSERM, BMGIC, U1035, F-33000 Bordeaux, France \\ Correspondence: Corinne Faucheux, INSERM U1035, BMGIC, Dermatology Team, 146 rue Léo Saignat, \\ Bordeaux University, 33076 Bordeaux cedex, France. E-mail: corinne.faucheux @u-bordeaux.fr
}

Received: July 1, $2020 \quad$ Accepted: July 30, $2020 \quad$ Online Published: August 8, 2020

doi:10.5539/hes.v10n3p101 URL: https://doi.org/10.5539/hes.v10n3p101

\begin{abstract}
COVID-19 pandemic is a disaster and prolonged crisis that has disrupted the education of millions of students with the closure of schools and universities in world-wide. This hard situation rises the necessity to develop a new teaching method to solve the problem of the massive disruption specially to practice work access. The goal of this paper is to set-up an innovative teaching approach for practical work. The comic as a new self-paced e-learning product to teach bench-top practice: the "CoViBE" which means $\underline{\text { Comic }}$ Virtual Bench-top Elearning. For using comics to transform practical work sessions by distance you should at first list all the steps that you need to perform your experiment. Then, you choose the actors and material images. For the third step, you have to decide how many frames you need to your comic trip to develop the following instructions: How to do, What to do, What not to do and What to ask. Moreover, you need to provide flashbacks to remind students what kind of knowledges they need to carry on their experiment; the final step is to include humor. Using online survey, positive feedbacks of 179 students on the CoViBE impact about their learning of practical work allowed us to determine around $80 \%$ of satisfaction. Finally, during any other situations for the training period, the CoViBE concept could be used in the future to complete practical work session for revisions, for the internationalization of this education system through distance work and for a hybrid education system.
\end{abstract}

Keywords: bench-top practice, comic, CoViBE, elearning, university, biology

\section{Introduction}

The COVID-19 pandemic is a health emergency crisis like armed conflict and natural disaster affecting education in world-wide. The lockdown of schools, colleges and universities not only interrupted the teaching for students but it also banned practical work education system. Based on latest UNESCO reporting, these nationwide lockdowns are impacting over 1.5 billion students which represent $90.2 \%$ of total enrolled learners in 191 countries (UNESCO, 2020). According to these unprecedented problems on education, we need to develop an innovative and coherent method to overcome the pandemic impact and to give students right to quality education.

E-learning exists and many universities practice this virtual method to teach by distance using slides, videos, and audios for tutorials. Especially, videos are useful to learn science practices at the bench-top. But are they performant enough to teach technical background and methodology to students? Why don't we create a new way to teach practicing bench-top techniques by benefiting from the most common and known mistakes to learn the proper way for the practical work. This idea came during the social distance needed during the COVID-19 epidemic period. All types of face to face teaching were stopped to engage virtual learning. How to teach practical work session respecting students' comfort to learn upon their own pace? Rather than videos, we decided to create a slower dynamic dimension using comic's image fluidity associated with texts or thinking, advertising mistakes and humor in order to obtain student's attention, increasing the learning capacities: the comic as a new 
self-paced e-learning product to teach bench-top practice. Nevertheless, this innovative e-learning method has emerged during the strange period of COVID-19, we called it the "CoViBE" which means Comic Virtual Bench-top Elearning.

Comics have existed for over 30,000 years, since the first cave paintings. Comics are already used in preschool or primary school in the language and literacy program (Koutníková, 2017; Wallner, 2017). Creating comics explain History, and other big subjects such as Biology to the general public where humorous illustrations make biology's most complex concepts entertaining and easy to grasp (Gonick \& Wessner, 2019). Comic book-based intervention in order to increase the knowledge about pathology such as epilepsy has been tested on a sample of high school students (Cicero et al., 2020). Using comics as communication strategy in teaching students in an Undergraduate Management Program has been described (Silva et al., 2017). One publication summarizes the available evidence across disciplines, highlighting the cognitive mechanisms that may underlie the effects of visual narratives and so, the use of potential comics in science communication (Farinella, 2018). However, the potential of comics in cell biology practical work learning has not been considered yet. The idea of using comics to teach biology techniques during practical work came from the fact that pictorial illustrations improve students' learning from text (Carney \& Levin, 2002). Although storytelling often has a bad connotation within sciences (Katz, 2013), new studies explore the potential of narrative in communicating science (Avraamidou \& Osborne, 2009; Dahlstrom, 2014). Actually, emerging research shows that comics and graphic novels are motivating, support struggling readers, enrich the skills of accomplished readers and are highly effective at teaching sometimes dull or dry material in subject areas such as science and social studies (Hosler \& Boomer, 2011; MANNO, 2014; McCroskey \& Richmond, 1983; Smetana et al., 2009).

This first generation of CoViBE is about immunocytofluorescence (Im et al., 2019), a highly used technique in biology and so a usual bench-top technique concerning students at the undergraduate program of Bordeaux University (second year of Bachelor's degree in life sciences). The aim of this paper deals with the use of comics for teaching practical work sessions by distance and the study of its influence on student's learning.

\section{Methods}

\subsection{Prerequisite}

Teacher doesn't need to be a famous cartoonist or an expert in design. Of course, some downloaded images from internet have to be mentioned when necessary. New images can even be created from practical teaching experience.

Experience as teachers and researchers is useful when teachers have already taught the practical work in face to face with students from Bordeaux University before lockdown. For the first CoViBE, the practice session is about immunocytofluorescence but the CoViBE concept can be used for any technical practice.

Immunocytofluorescence is a basic technique in cell biology consisting of "staining" a cellular protein using specific antibodies (Im et al., 2019). In our case, highlighted proteins were vimentin (expressed in cell cytoskeleton) and nuclear laminin (expressed in nucleus). Usually, the sample is composed by animal cells grown on glass coverslips, which are chemically fixed.

First, teachers will have to list all the steps that they need to perform your practical work. For example in this paper, for the coverslip called EXP (experiment), the protocol is composed of eleven steps: (1) chemical fixation such as paraformaldehyde (step performed by teachers under safe conditions), $(2,4,7,9)$ wash steps using buffer such as Phosphate Buffer Saline or PBS, (3) permeabilization using detergents such as Triton X-100 allowing antibodies to enter the cell, (5) saturation using sticky proteins as Bovin Serum Albumin or BSA to avoid no specific reactions, $(6)$ the use of primary antibodies $(\mathrm{Ab})$ which specifically recognize their target proteins while taking into account the choice of species to select the adequate primary $\mathrm{Ab},(8)$ the use of secondary $\mathrm{Ab}$ that bind to and are different from primary Ab species, (10) a last wash with water to remove salt crystals and finally (11) mounting of the coverslip with mounting medium to observe under a microscope. In our case, the secondary antibodies were conjugated with fluorophores, so students will need to use a fluorescence microscope. Furthermore, in the case of detection of two distinct proteins, the fluorophores of the secondary Ab must vary in their wavelength spectrum to distinguish from the fluorescent color of each protein during microscopic observation. In this practical work, the two studied proteins, vimentin and laminin, will be observed in green and red fluorescence respectively. The same experiment called NEG (negative) is performed without primary antibodies to check secondary antibody specificity.

All these basics knowledges can be taught in a lecture or tutorial (as slide presentation) by explaining the use of the materials according to the different steps, and the mechanism of fluorescence can be explained in another 
tutorial. Additional teaching may be included such as how to calculate dilutions of solutions, or how to choose antibodies and incubation times depending on student's level. All tutorials can be online (E-learning). Once all basic and theoretical knowledges are learnt, teachers can start their comic. To complete the training of students, this theoretical knowledge is recalled in the form of flashbacks in CoViBE.

\subsection{CoViBE Designing}

The second step is to decide how many actors (actors' choice should be related to your main topics) are needed and what will be their images for the comic? Teachers can draw their characters or can get some images from internet respecting copyrights. Whatever are the images taken from the web, the source must be mentioned.

For the third step, teachers have to decide how many frames are needed to the comic trip, and how to represent a movement through static images? It's fairly simple, one move is equal to two frames: this is the How to do. Do not forget that you need more frames for teachers to give instructions related to technical protocol (What to do), to explain mistakes (What not to do), and some frames will be used for students (What to ask). Additional frames can be added during comic designing to avoid too much text in one frame.

Moreover, teachers need to provide flashbacks to remind students what kind of knowledges they need to carry on their experiment. Flashbacks are related to tutorials that teachers gave before reading the comic as described above: immunostaining steps or calculations. Furthermore, a video link may be included to explain additional practices, for example the use of micropipettes depending on student's level.

The final step is to include humor. Humor is a personal skill, and teachers can use their personal experience acquired during practical works with students.

\subsection{Assessment of the CoViBE Impact on Life Science Students from Bordeaux University (Biology Department)}

Finally, to evaluate the impact of CoViBE to teach virtual practical work session, concerned students were questioned using a (obviously online) survey (anonymous and voluntary reply). Many questions have been asked:

- Did the CoViBE help you to visualize the practical work flow (the feeling of movement)?

- Did the CoViBE help you to understand the practical work (the different steps of the manipulation)?

- Would you have preferred a video instead?

- Would you have preferred a descriptive file (with text only) instead?

- Did the CoViBE allow you to learn at your own pace (rather than a video)?

- Did the CoViBE encourage you to ask yourself more questions in order to better understand the manipulation (compared to a text file)?

- Did the humor of these CoViBE allow you to take a quick break to better focus on reading?

- Is the drawing of the characters important?

- Do you think you could reproduce the protocol using the CoViBE?

- For those who took the practical course face to face did the CoViBE help you to complete some points too quickly passed in the practical room?

- Do you have any other suggestions?

This online survey was available 2 weeks after the CoViBE publication. Only students registered on the taught module were allowed to respond to the survey. Two groups of the same cohort have replied: students who followed the practical work face to face (76 Students) and students who did not (103 students). Original questions of this survey (in french) are provided in Appendix (Appendix B, Fig.A-C).

\subsection{CoViBE Publication}

Two different CoViBE were designed and published on French teaching platform of the Bordeaux University. The French lockdown started the $16^{\text {th }}$ of March and we supplied to students the first CoViBE (Episode 1, Fig.1), two weeks later. Following the first CoViBE success, we designed a second CoViBE (Episode 2, Appendix A) related to the use of fluorescence microscope just a week after. 

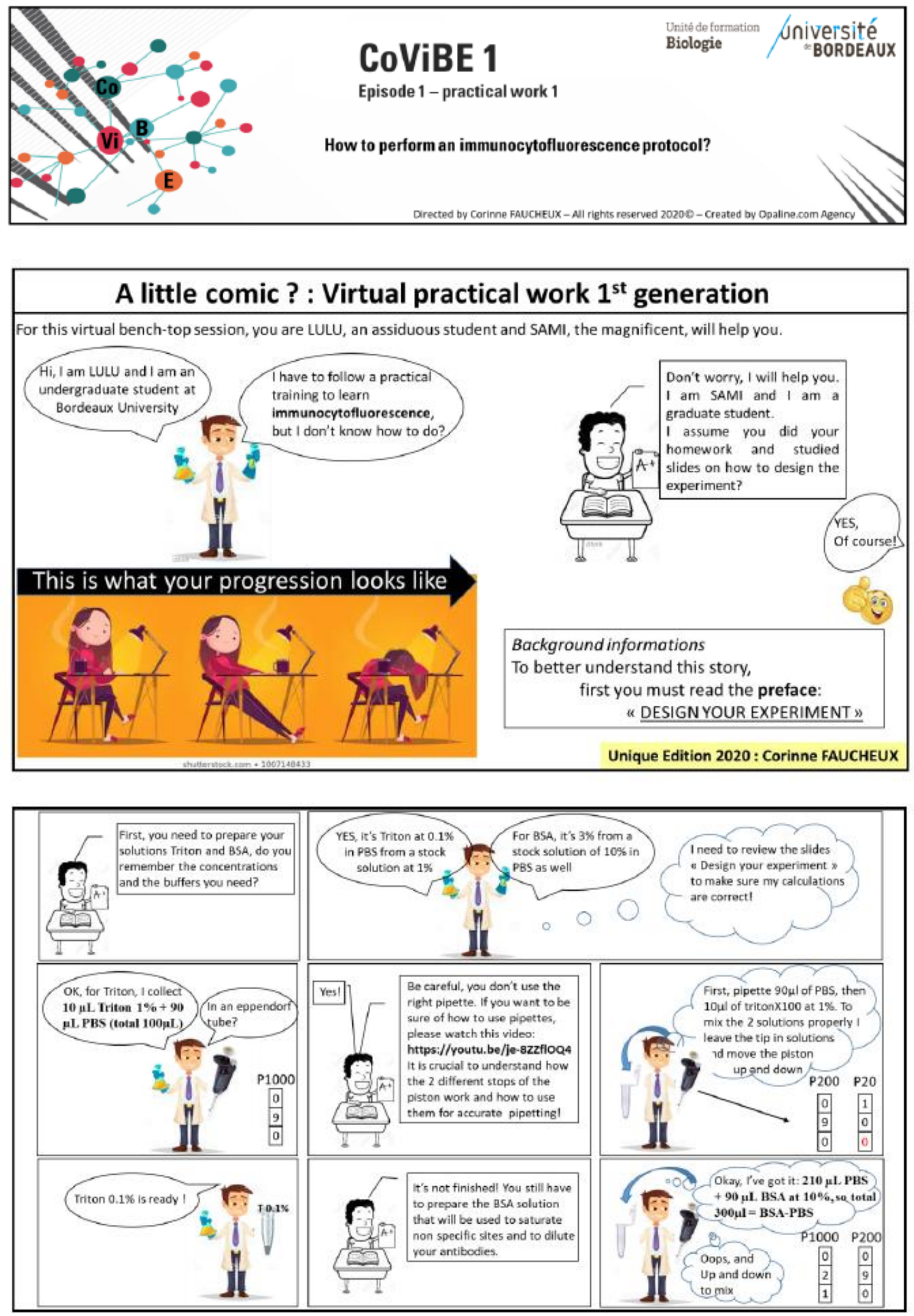



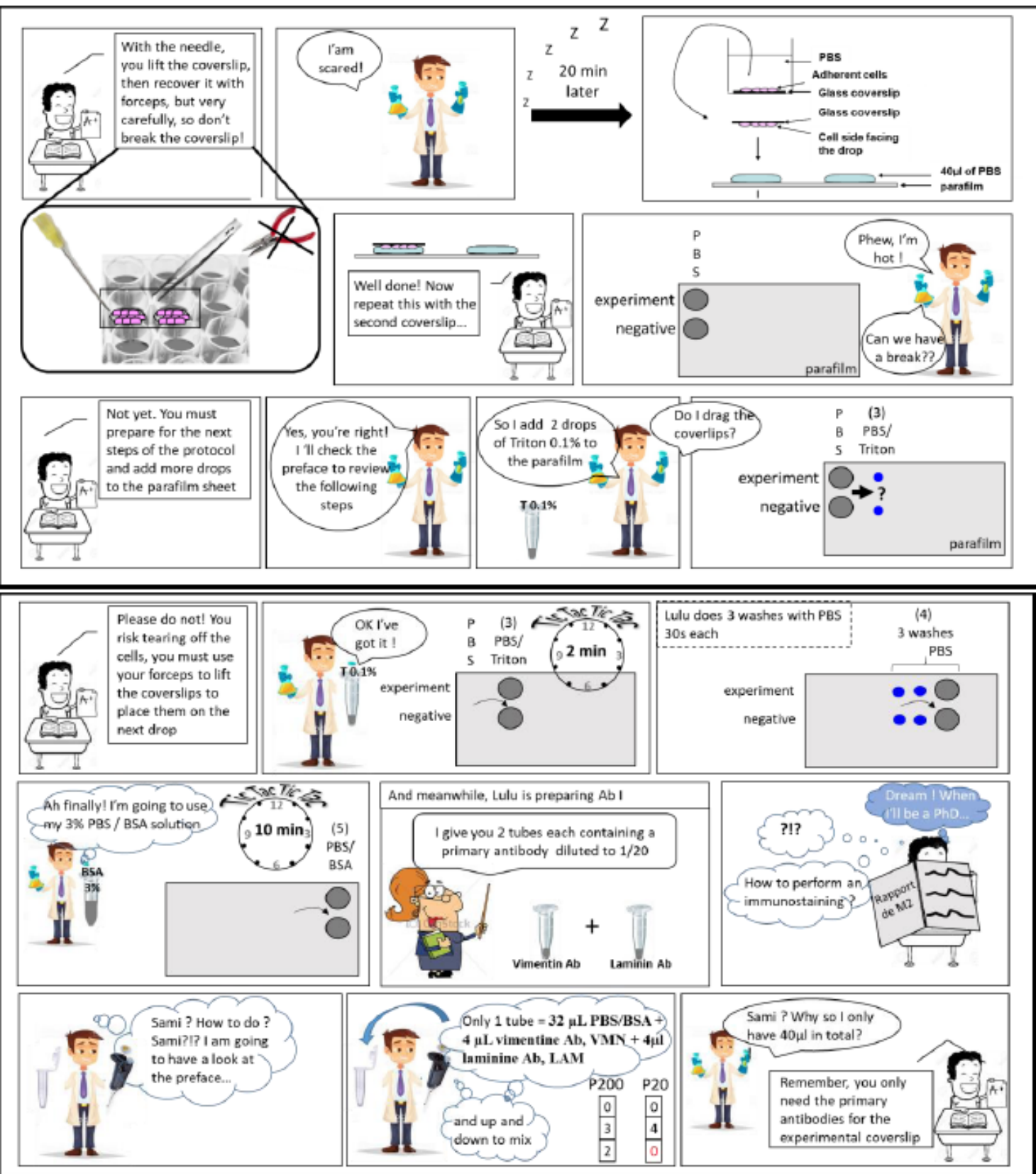


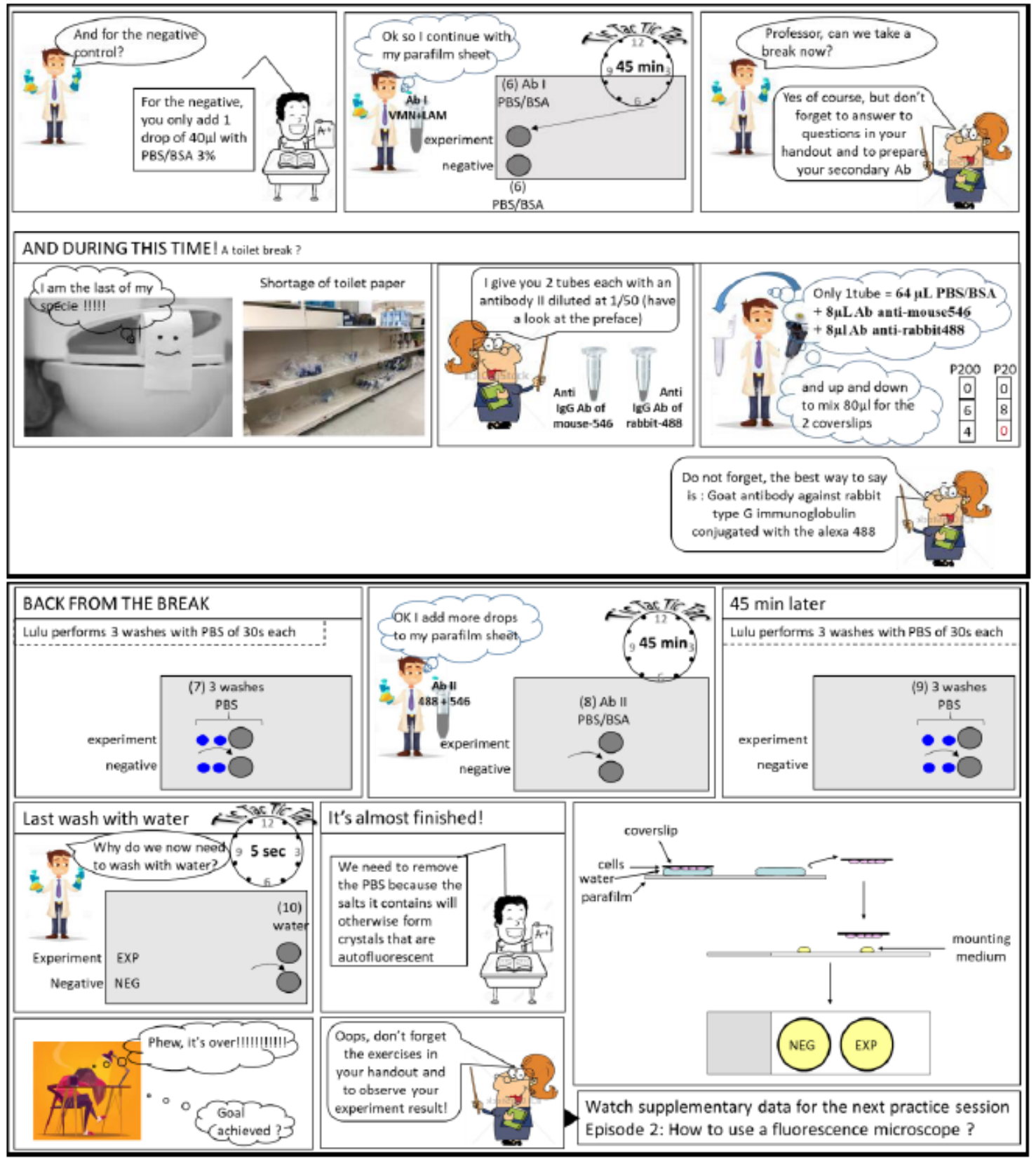

Figure 1. Episode 1 of the CoViBE

CoViBE 1: How to perform an immunocytofluorescence protocol? This comic trip is composed of eight frames showing the bench-top handling and materials needed, instructions and student questions (speech bubbles in black) and thinking (thinking bubbles in blue). Reading direction is from left to right and from top to bottom. This new teaching experiment leads to Episode 2 in order to train students to the practice of the fluorescence microscope (see CoViBE 2, Appendix A)

\section{Results and Discussion}

\subsection{Survey Results}

In order to find out what impact the CoViBE had on their learning of practical work, many questions were asked anonymously in the form of an online survey. 179 students from the same cohort replied: 76 students followed the practical work face to face and 103 students who did not. Results are shown using pie chart in figure 2 . Around $80 \%$ of students agree to approve that (i) comics help them to visualize and understand the practical work and (ii) comics rather than text file helped them to learn virtual practical work (Fig.2A, 2B and 2D). 
Although $62 \%$ would have preferred a video (and only $18 \%$ for a text only), $78 \%$ admit that CoViBE allowed them to learn at their own pace rather than a video (Fig. 2C and 2E). For the following questions; Did the CoViBE encourage you to ask yourself more questions in order to better understand the manipulation (compared to a text file)?, 67\% positively answered (Fig.2F). Concerning humor, it allowed $87 \%$ of students to have a break to better focus on reading (Fig. 2G) and 36\% thought that funny characters are important against only $9 \%$ that didn't care about the sense of humor for the characters (Fig. $2 \mathrm{H}$, the majority $(55 \%)$ thought that characters are not important but when they are funny, it's better). Finally, $75 \%$ thought that they could reproduce the protocol using $\mathrm{CoViBE}$ and for $71 \%$ who practiced face to face, this cosmic helped them to complete some points too quickly passed in the practical room (Fig.2I and 2J). Original results about the online survey were provided in Appendix (Appendix B, Fig.D-H).
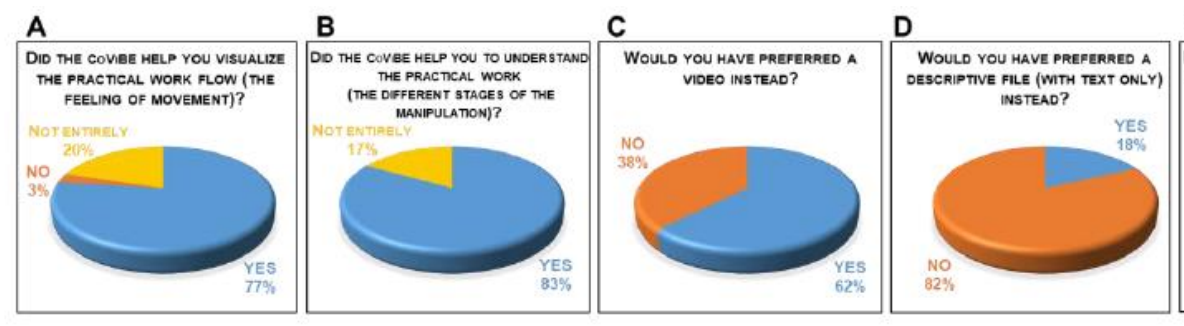

E
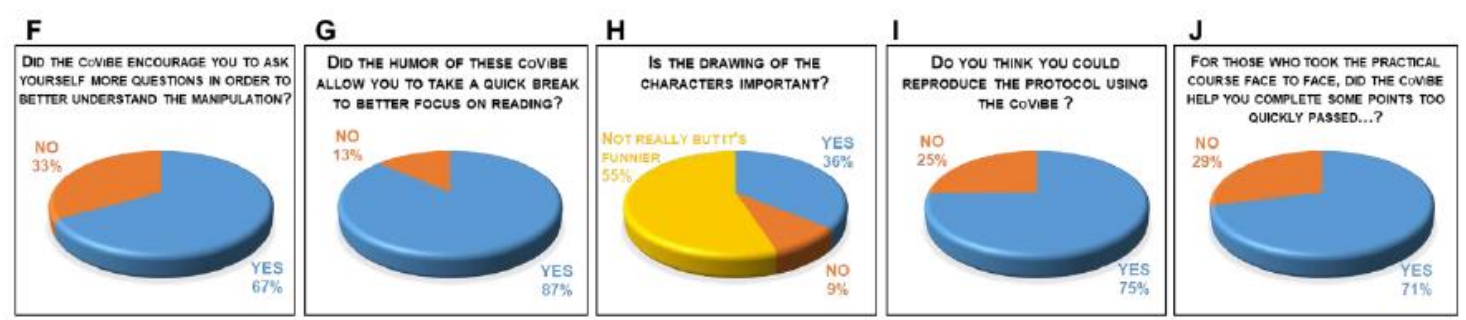

Figure 2. Survey results. Ten questions were proposed to students

A. Did the CoViBE help you visualize the practical work flow (the feeling of movement)?

B. Did the CoViBE help you to understand the practical work (the different stages of the manipulation)?

C. Would you have preferred a video instead?

D. Would you have preferred a descriptive file (with text only) instead?

E. Did the CoViBE allow you to learn at your own pace (rather than a video)?

F. Did the CoViBE encourage you to ask yourself more questions in order to better understand the manipulation?

G. Did the humor of these CoViBE allow you to take a quick break to better focus on reading?

$\mathrm{H}$. Is the drawing of the characters important?

I. Do you think you could reproduce the protocol_using the CoViBE?

J. For those who took the practical course face to face, did the CoViBE help you complete some points too quickly passed in the practical room? (76 students have learnt the practical course face to face answered to this question).

This online survey was anonymous and all students came from the same cohort. 179 students answered: 76 students followed the practical work face to face and 103 students who did not. Results are expressed as a percentage (\%) compared to total answering students. Original documents are shown in Appendix (Appendix B).

\subsection{Time-Spaced Publication}

During the lockdown, the fact that students had worked on two episodes spaced out one week corresponding to two practical work sessions allowed them to acquire knowledge at their own pace in front of this huge amount of online documents. In a recent study during online course about introductory psychology, it has been proved that self-regulated spacing in a massive open online course is related to better learning (Carvalho et al., 2020). These rest periods allowed the students to consolidate the achievements as it was shown that offline processing of prior memories was correlated with better subsequent learning (Dudai, 2012; Schlichting \& Preston, 2014).

\subsection{Own Pace Learning}

Survey results answered directly or indirectly to several questions about own pace learning (Fig. 2). Comics are not static. The fact of moving from one image to another symbolizes movement and therefore bench-top 
manipulation (Fig. 2A-B), the student advances at his/her own pace, can very well linger on an image to well understand it and also taking his time to read the associated texts: sequencing promotes understanding (Fig.2E, $2 J)$. Texts are short, punchy and effective which can be another motivator. The fact that text is reduced make comics manageable and motivate reluctant readers: $80 \%$ of students approved that comics helped them to visualize and understand the practical work rather than text file (Fig. 2D).

\subsection{Images and Memory}

Visual information is easily memorable; human respond to and process visual data as images better than any other type of data. The human retina would transmit data at roughly the rate of an Ethernet connection (Koch et al., 2006). Moreover, it has been shown the impact of illustrations on memorizing of short stories where illustrated short stories are likely to enhance the recall of such texts by learners (Ghazanfari et al., 2014). Images enrich understanding text (Fig. 2C-D).

\subsection{To be or not to be funny?}

Humor is an asset; it has already been described to increase learning benefits for students (Korobkin, 1988). It will keep the attention of students and avoid losing their concentration: a few seconds of relaxation to be able to better focus on the images and texts (Fig. 2G). The humor is like a rest or a break for neurons, a different sort of works uses different parts of brain but they are connected. Humor generates creativity and as it has been shown, conventional creative thinking and an understanding of humor share neural mechanisms linked to inspiring cognition (Perchtold-Stefan et al., 2020). Nevertheless, humor generates physiological and psychological benefits: a factor of well-being and pleasure when working, it is also a factor of satisfaction for the student.

\subsection{Drawing Skills}

To create a comic, teachers can draw their own actors but they don't have to be good at art, they have to be right (McDermott et al., 2018). They can illustrate a round with 2 eyes and a nose and it all depends on their creativity. However, 55\% of students do not consider the characters as important but when they are funny, it is better. $36 \%$ think that characters are important against only $9 \%$ who did not (Fig.2H).

\subsection{Useful Flashbacks}

The last tool of the CoViBE is flashbacks. The theory is generally learnt during courses (text or slide) and linked to several flashbacks included in the CoViBE. Flashbacks are essential: (i) they make the link between practical work and theoretical knowledge, (ii) they also lead to a fruitful discussion and (iii) they inform students about what they need to know. It has been suggested that subjective reactivation of prior knowledge during educational learning, such as flashback images in our paper, enhances memory integration (van Kesteren et al., 2018).

\subsection{CoViBE Leads to Discussion}

The CoViBE encourage students to ask more questions in order to better understand the manipulation (Fig. 2F). The comics are like a desirable support to the discussion. Several chats and virtual classes have been done to discuss around the comic supports. Due to the frames associated images and short texts, students can formulate their own interrogations and they can answer to each other without repeating text and better than videos. Based on our experience during practical work, we have tested the learning of Histology (another life science bench-top technique) using videos (face to face and online learning). There was no dialog initiated between students and teachers and little information has been stored: videos provide too much information at a short time-lapse.

In collaboration with a graphic design company, we have designed another more original and more didactic form while respecting a more appropriate sense of reading and with more time rest, a second generation of CoViBE that can be used as a book (see Appendix C).

Finally, the main question is: Does CoViBE reproduce a practical work session? $75 \%$ of students think that they could reproduce the protocol using the comics (Fig. 2I).

\section{Conclusion}

At the result of the COVID-19 lockdown, we have designed two CoViBE for students to teach two practical sessions related to face to face theoretical tutorial and course. The first one, CoViBE 1 was teaching how to perform an immunocytofluorescence. In response to the CoViBE 1 success, we agreed to design the episode 2 addressed to the same students one week later. The CoViBE 2 helped them to learn how to use a fluorescence microscope, a way to observe their immunocytofluorescence results and to apply their knowledges on fluorescence mechanism (see CoViBE 2 in Appendix A).

Regarding to the assessment, this comic experiment was a success to learn practical work and to answer to four 
fundamental questions: How to do, What to do, What not to do and What to ask. In order to promote this innovative concept of virtual practical work learning, we carried out a conceptualization of the CoViBE (Fig.3). In addition to the answer of these four main questions, the CoViBE concept allowed students to use and develop many skills: (i) increase concentration and memorable knowledges, (ii) imagine the image movement, (iii) increase the interest and curiosity to learn at their own pace and the relaxing time and finally (iiii) obtain a way to check if they acquired the theoretical background linked to flashbacks (Fig.3). Moreover, the same CoViBE can be translated in all languages.

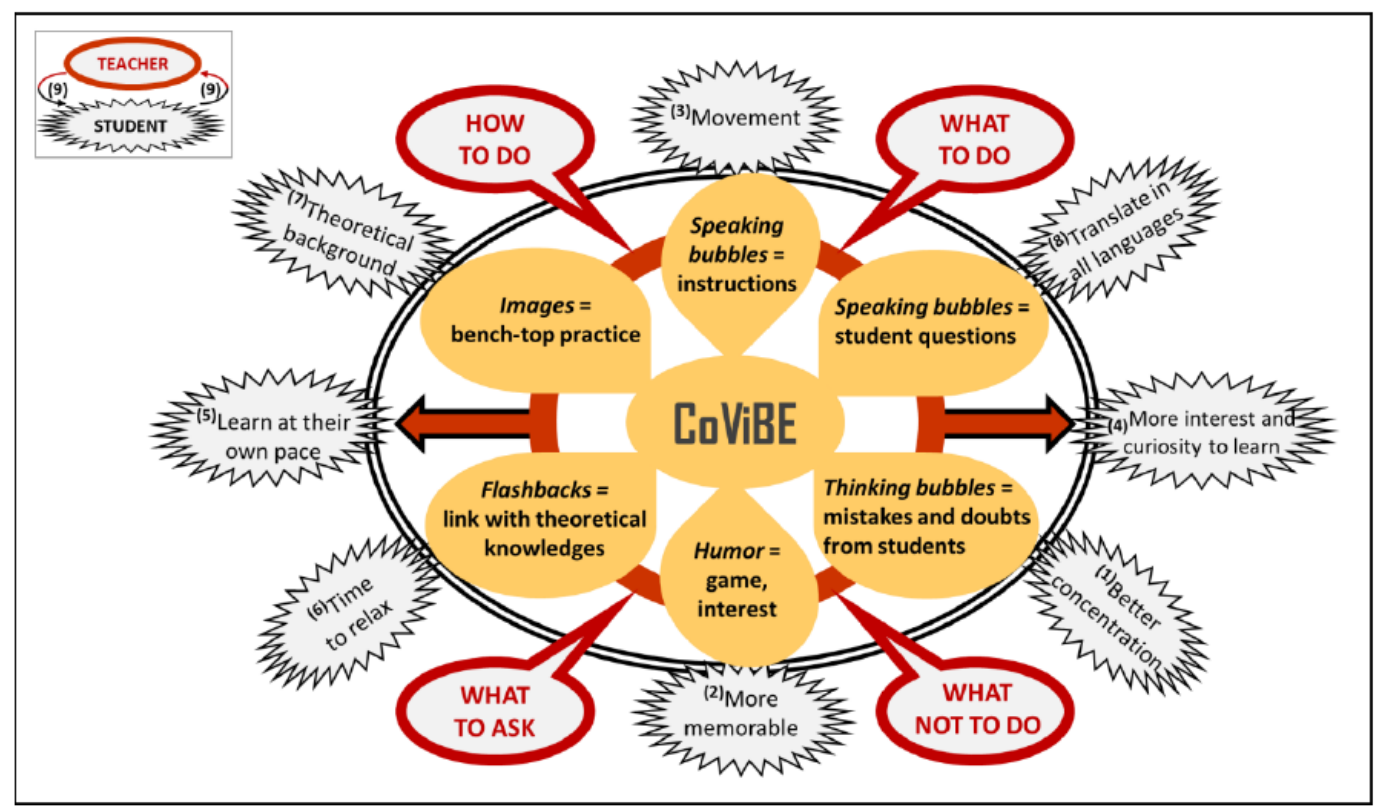

Figure 3. CoViBE concept mapping

Light orange petals symbolize different steps and tools to design a comic: images, speaking and thinking bubbles, humor and flashbacks. Practical questions are described in brown bubbles linked to the first brown circle: WHAT TO DO, HOW TO DO, WHAT TO ASK and WHAT NOT TO DO. These four main questions are related to teachers. Thanks to these questions, students acquire technical skills but not only! CoViBE displays many other advantages to help consolidate and develop many skills: increase (1) concentration and (2) memorable knowledges, (3) imagine the image movement, increase (4) the interest and curiosity to learn (5) at their own pace and (6) the relaxing time and finally (7) obtain a way to check if they acquired the theoretical background linked to flashbacks. Moreover, the same CoViBE can be translated in all languages (8). These learning benefits in reaction to the CoViBE are listed in black broken line circles (see number superscripts from 1 to 9) linked to the outside double line circle related to students. This innovating elearning support leads to discussion between Teacher and Student (9).

The CoViBE can be been compared to the model about the three phases of learning: surface, deep and transfer (Hattie \& Donoghue, 2016). However, the CoViBE concept emphasizes the value of learning more centrifugally from the inside (the four fundamental practical questions listed above) to the outside (additional skills acquired or developed).

The majority of students think that they could reproduce the protocol using the comics. In addition, CoViBE (online or print form) can be used for review before training assessments and represent a valid and valuable source of technical knowledge. Even in any other situation, the CoViBE can be an additional pedagogical support enabling students to review practical work in a synthetic way.

From now, many comics prove to be an excellent vehicle for scientific information to combine knowledge with humor and its multiple narrative, visual and interactive possibilities allow it to decipher (and clear) very complex scientific fields.

However, using our personal experience of basic teaching, a discussion is essential to answer all the questions related to comics. Of course, a video could help but would be much less practical as a basis for discussion online. During virtual classroom or chat, number of students have discussed with the teacher using the CoViBE as the 
visual document. The CoViBE fits to the "Three E's of Comics" of Josh Elder, founder and president of "Reading With Pictures" (MANNO, 2014):

- Engagement, with written language and juxtaposed sequential images. Readers must actively make meaning from the interplay of text and images, as well as by filling in the gaps between panels,

- Efficiency, with large amounts of information in a short time,

- Effectiveness, students not only learn the material faster, they learn it better by processing text and images together.

However, one limitation can emerge using the CoViBE concept because it doesn't reflect the real idea about managing the experiences: how to solve the problems occurred during the experience.

To conclude, the CoViBE concept can be a valuable substitute for practical work as well as a virtual classroom led by a teacher, and this new way of E-learning could be used for the internationalization of effective distance bench-top technique learning, for a hybrid education system (face-to-face and distance learning) and could be extended to master's students. For nearly a decade, the rise of science comics has thus highlighted the potential of comics as a tool for scientific mediation, in the same way as popular science videos. The CoViBE opens a stimulating and initiating dimension of teaching federating a double conceptship: the virtual technical practice of theoretical ideas associated with learning at own pace.

\section{Acknowledgements}

The practical courses are supported by the University of Bordeaux in the Biology Unit Training. This study has received financial support from the French State in the frame of the "Investments for the future" Program. We thank the students for responding honestly to the online survey. We also thank Sylvie TRONCHE for the free design of another more original and more didactic form of CoViBE and for the creation of the CoViBE logo (Opaline, Grand'rue-19500 Meyssac-FRANCE, opaline.com@ wanadoo.fr). We thank Dr Jan-Adrianus Veenstra for carefully reading the English version of comics.

\section{Copyrighted Material}

Every effort has been made by the authors to trace copyright holders and for the citation of copyrighted images to design the CoViBE.

\section{Data Availability}

All data generated or analyzed during this study are included in this published article and in the appendix.

\section{Competing Interests}

The authors declare that there are no competing interests.

\section{Author Contribution}

Corinne Faucheux created the comics (CoViBE 1 and 2, first and second generation), designed the CoViBE concept mapping, coordinated the paper and led the writing. All authors contributed to writing and editing of the paper and approved the final manuscript.

\section{References}

Avraamidou, L., \& Osborne, J. (2009). The Role of Narrative in Communicating Science. International Journal of Science Education, 31(12), 1683-1707. https://doi.org/10.1080/09500690802380695

Carney, R. N., \& Levin, J. R. (2002). Pictorial illustrations still improve students'learning from text. Educational Psychology Review, 14(1), 5-26. https://doi.org/10.1023/A:1013176309260

Carvalho, P. F., Sana, F., \& Yan, V. X. (2020). Self-regulated spacing in a massive open online course is related to better learning. Npj Science of Learning, 5(1), 2. https://doi.org/10.1038/s41539-020-0061-1

Cicero, C. E., Giuliano, L., Todaro, V., Colli, C., Padilla, S., Vilte, E., ... Nicoletti, A. (2020). Comic book-based educational program on epilepsy for high-school students: Results from a pilot study in the Gran Chaco region, Bolivia. Epilepsy \& Behavior, 107, 107076. https://doi.org/10.1016/j.yebeh.2020.107076

Dahlstrom, M. F. (2014). Using narratives and storytelling to communicate science with nonexpert audiences. Proceedings of the National Academy of Sciences, 111(Supplement_4), 13614-13620. https://doi.org/10.1073/pnas.1320645111

Dudai, Y. (2012). The Restless Engram: Consolidations Never End. Annual Review of Neuroscience, 35(1), 227-247. https://doi.org/10.1146/annurev-neuro-062111-150500 
Farinella, M. (2018). The potential of comics in science communication. Journal of Science Communication, 17(01). https://doi.org/10.22323/2.17010401

Ghazanfari, M., Ziaee, M., \& Sharifianfar, E. (2014). The Impact of Illustrations on Recall of Short Stories. Procedia - Social and Behavioral Sciences, 98, 572-579. https://doi.org/10.1016/j.sbspro.2014.03.453

Gonick, L., \& Wessner, D. (2019). The Cartoon Guide to Biology (William Morrow and Company).

Hattie, J. A. C., \& Donoghue, G. M. (2016). Learning strategies: A synthesis and conceptual model. Npj Science of Learning, 1(1), 16013. https://doi.org/10.1038/npjscilearn.2016.13

Hosler, J., \& Boomer, K. B. (2011). Are Comic Books an Effective Way to Engage Nonmajors in Learning and Appreciating Science? ${ }^{1}$. CBE-Life Sciences Education, 10(3), 309-317. https://doi.org/10.1187/cbe.10-07-0090

Im, K., Mareninov, S., Diaz, M. F. P., \& Yong, W. H. (2019). An Introduction to Performing Immunofluorescence Staining. In W. H. Yong (Ed.), Biobanking (Vol. 1897, pp. 299-311). Springer New York. https://doi.org/10.1007/978-1-4939-8935-5_26

Katz, Y. (2013). Against storytelling of scientific results. Nature Methods, 10(11), 1045-1045. https://doi.org/10.1038/nmeth.2699

Koch, K., McLean, J., Segev, R., Freed, M. A., Berry, M. J., Balasubramanian, V., \& Sterling, P. (2006). How Much the Eye Tells the Brain. Current Biology, 16(14), 1428-1434. https://doi.org/10.1016/j.cub.2006.05.056

Korobkin, D. (1988). Humor in the Classroom: Considerations and Strategies. College Teaching, 36(4), 154-158. https://doi.org/10.1080/87567555.1988.10532139

Koutníková, M. (2017). The Application of Comics in Science Education. Acta Educationis Generalis, 7(3), 88-98. https://doi.org/10.1515/atd-2017-0026

MANNO, M. (2014). Comics in the Classroom: Why Comics? (Thales Book, Vol. 4). Retrieved from https://www.thalesbooks.com/comics-in-education/

McCroskey, J. C., \& Richmond, V. P. (1983). Power in the classroom I: Teacher and student perceptions. Communication Education, 32(2), 175-184. https://doi.org/10.1080/03634528309378527

McDermott, J. E., Partridge, M., \& Bromberg, Y. (2018). Ten simple rules for drawing scientific comics. PLOS Computational Biology, 14(1), e1005845. https://doi.org/10.1371/journal.pcbi.1005845

Perchtold-Stefan, C. M., Papousek, I., Rominger, C., Schertler, M., Weiss, E. M., \& Fink, A. (2020). Humor comprehension and creative cognition: Shared and distinct neurocognitive mechanisms as indicated by EEG alpha activity. NeuroImage, 213, 116695. https://doi.org/10.1016/j.neuroimage.2020.116695

Schlichting, M. L., \& Preston, A. R. (2014). Memory reactivation during rest supports upcoming learning of related content. Proceedings of the National Academy of Sciences, 111(44), 15845-15850.

https://doi.org/10.1073/pnas.1404396111

Silva, A. B. D., Santos, G. T. D., \& Bispo, A. C. K. D. A. (2017). THE COMICS AS TEACHING STRATEGY IN LEARNING OF STUDENTS IN AN UNDERGRADUATE MANAGEMENT PROGRAM. RAM. Revista de Administração Mackenzie, 18(1), 40-65. https://doi.org/10.1590/1678-69712017/administracao.v18n1p40-65

Smetana, L., Odelson, D., Burns, H., \& Grisham, D. L. (2009). Using Graphic Novels in the High School Classroom: Engaging Deaf Students With a New Genre. Journal of Adolescent \& Adult Literacy, 53(3), 228-240. https://doi.org/10.1598/JAAL.53.3.4

UNESCO. (2020). How to Leave No One Behind as out of school becomes the norm - thoughts from Civil Society? Retrieved from https://en.unesco.org/news/how-leave-no-one-behind-out-school-becomes-norm-thoughts-civil-society

van Kesteren, M. T. R., Krabbendam, L., \& Meeter, M. (2018). Integrating educational knowledge: Reactivation of prior knowledge during educational learning enhances memory integration. Npj Science of Learning, 3(1), 11. https://doi.org/10.1038/s41539-018-0027-8

Wallner, L. (2017). Speak of the bubble - constructing comic book bubbles as literary devices in a primary school classroom. Journal of Graphic Novels and Comics, 8(2), 173-192.

https://doi.org/10.1080/21504857.2016.1270221 


\section{Appendix}

\section{Appendix A}
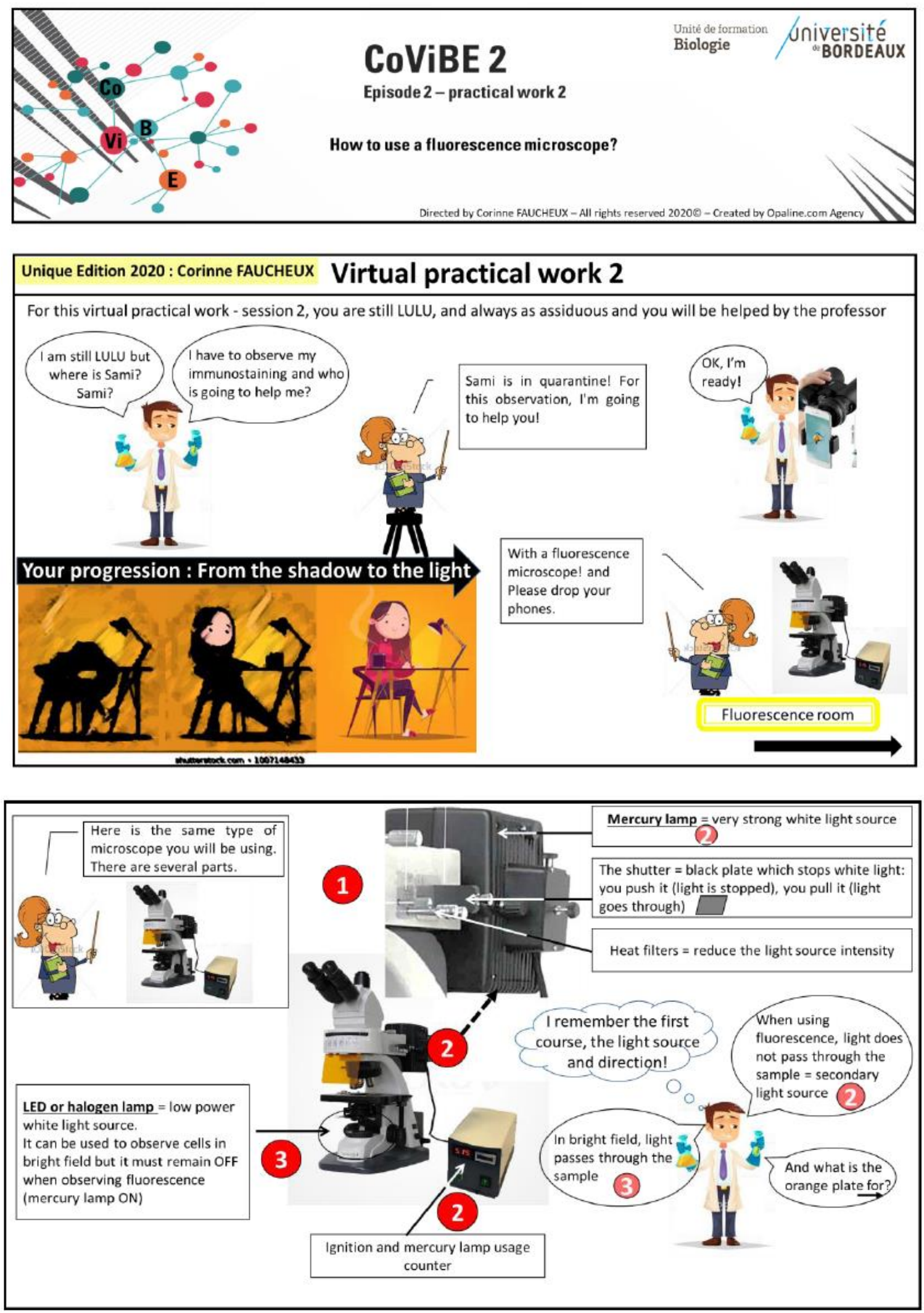

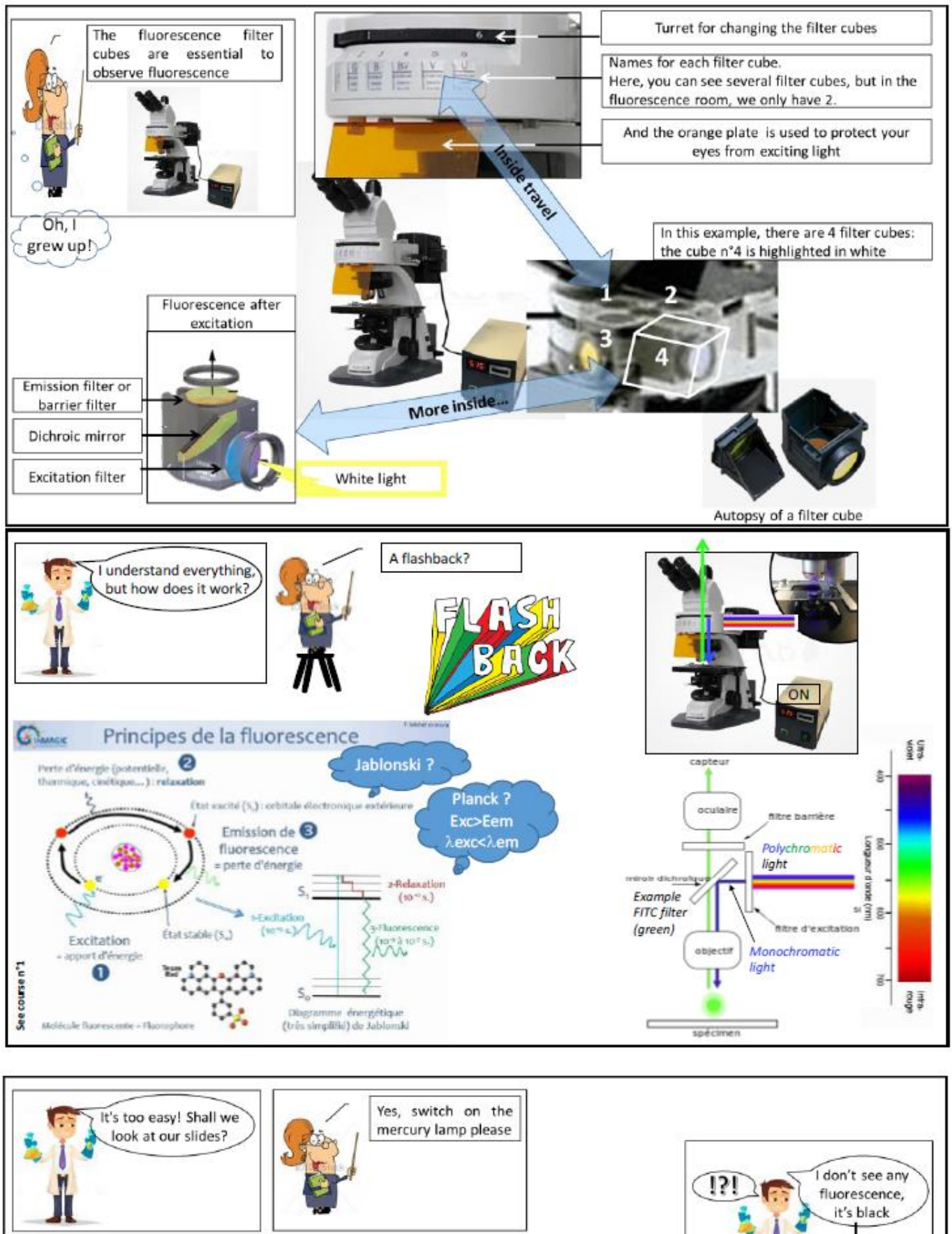

LULU places the glass slide on the stage(1), switches on the mercury lamp (2), positions the filter cube to excite in the blue (3) and opens/pulls the shutter to let the light path through the microscope objective.
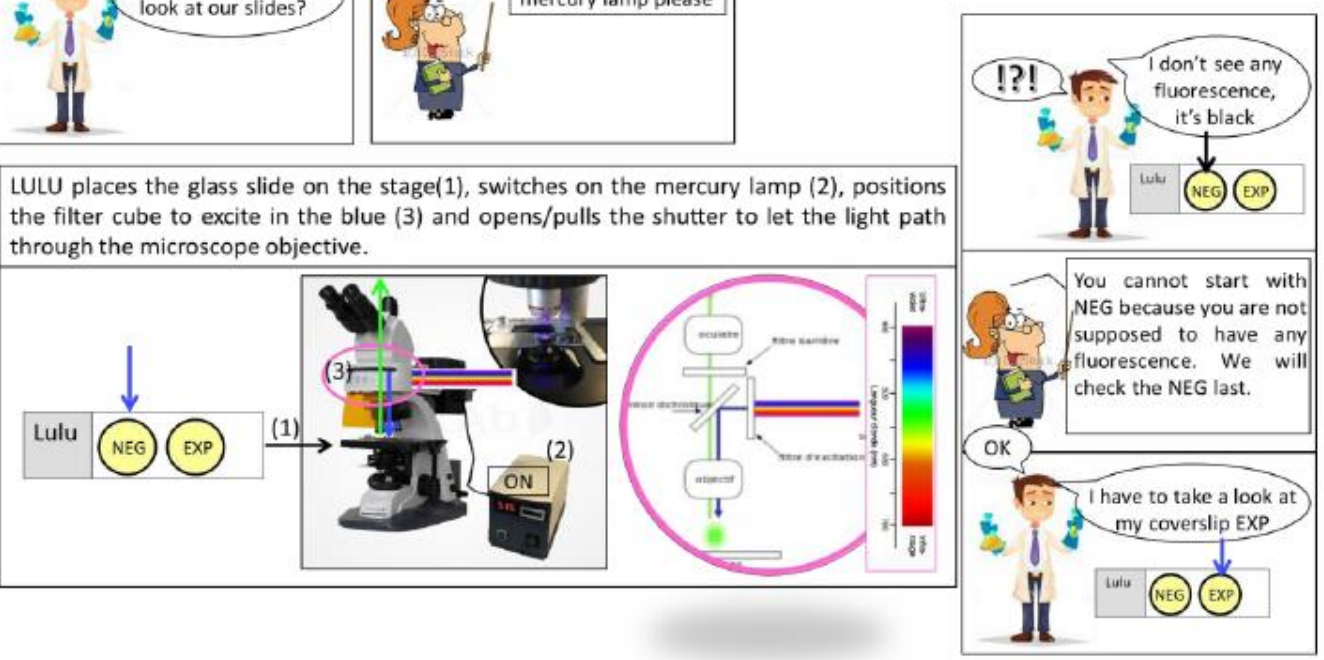

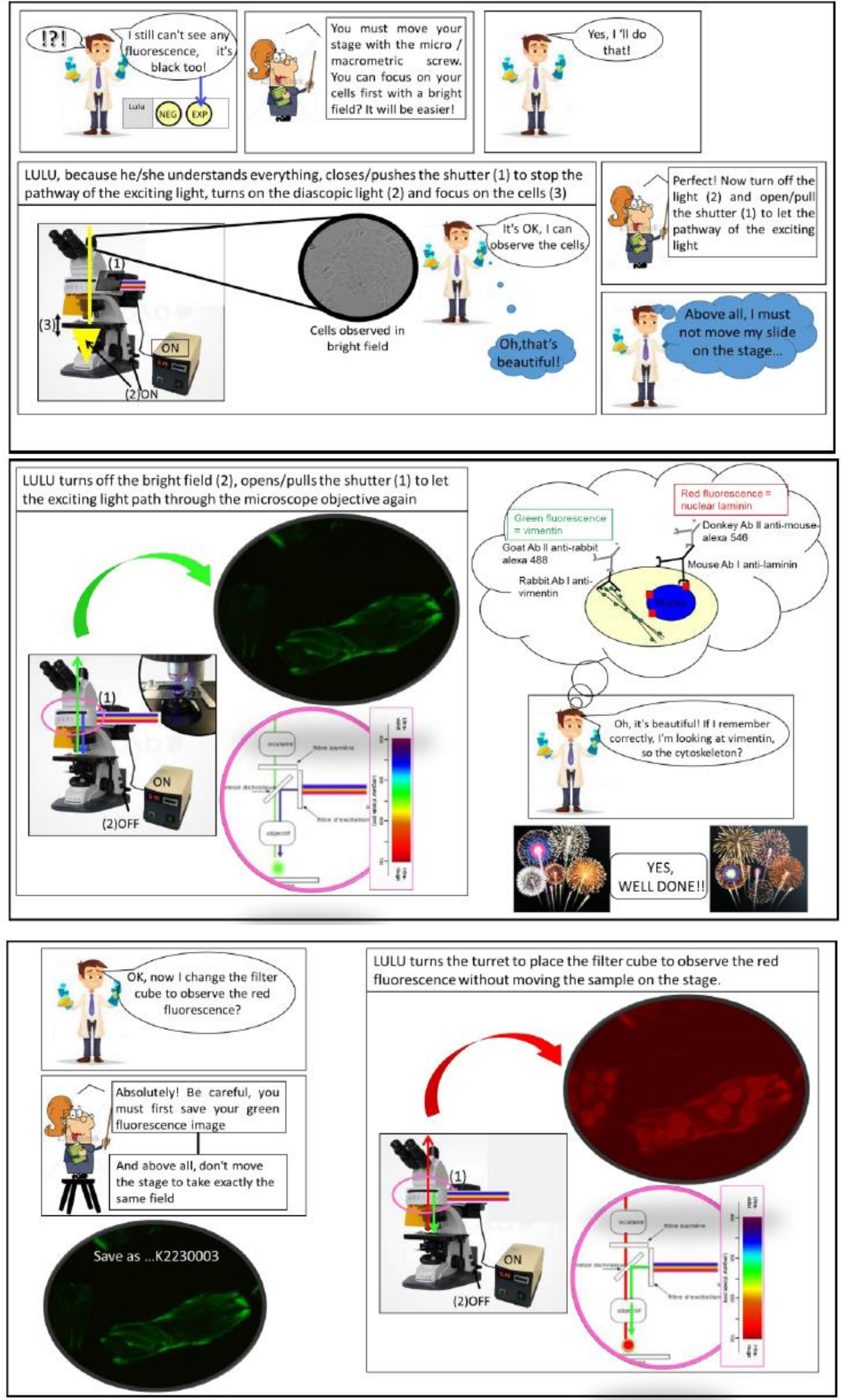

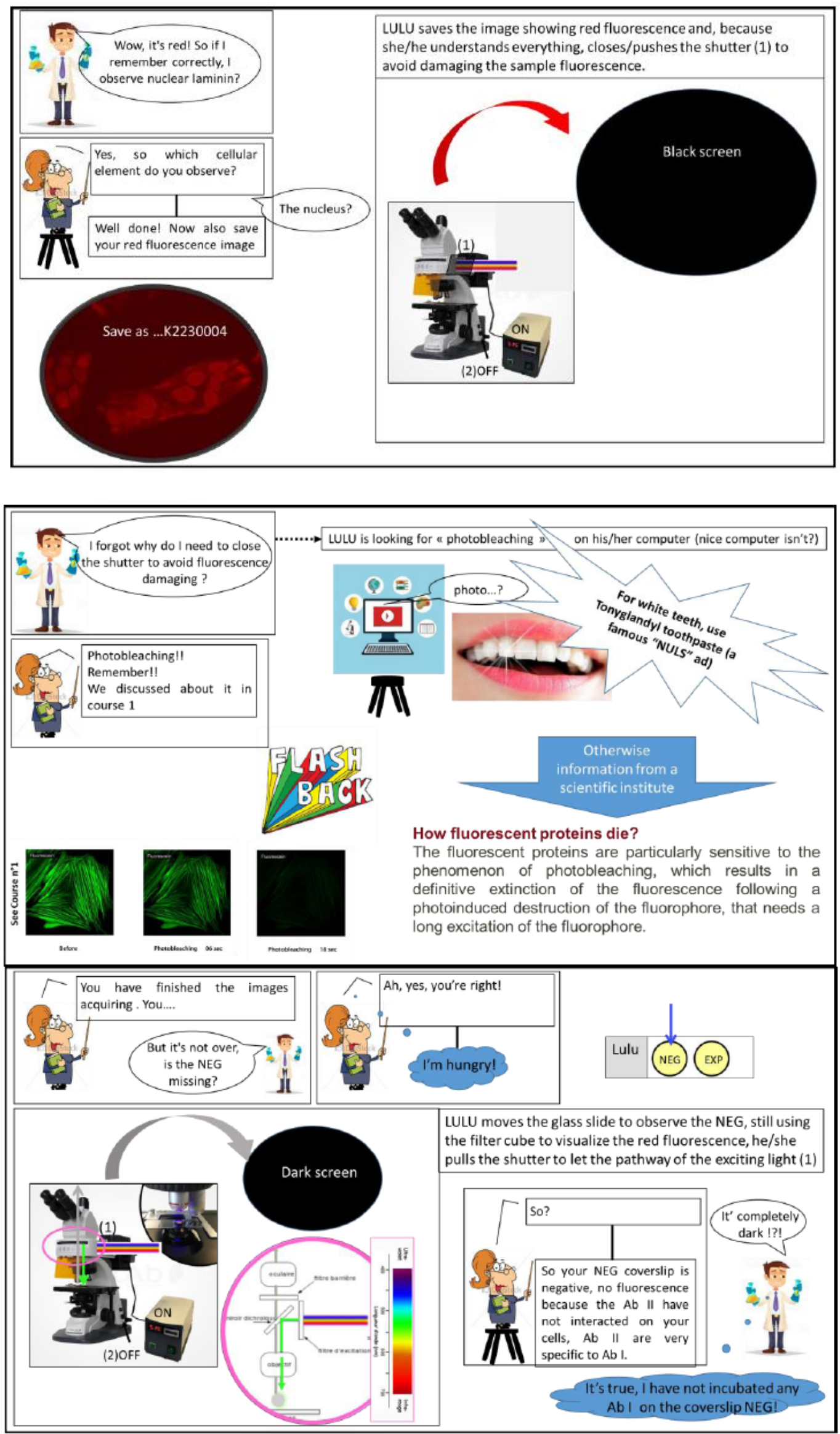

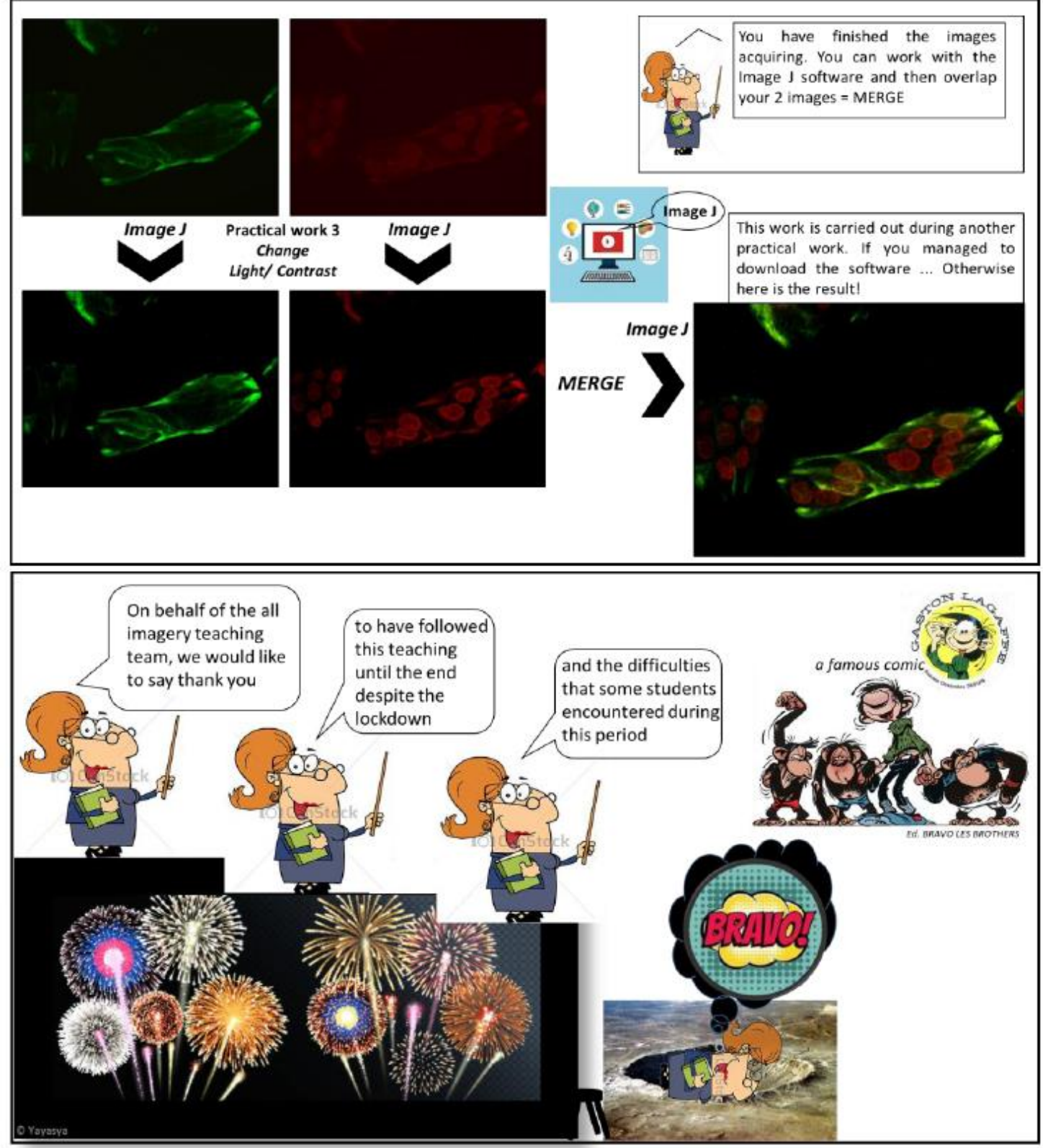


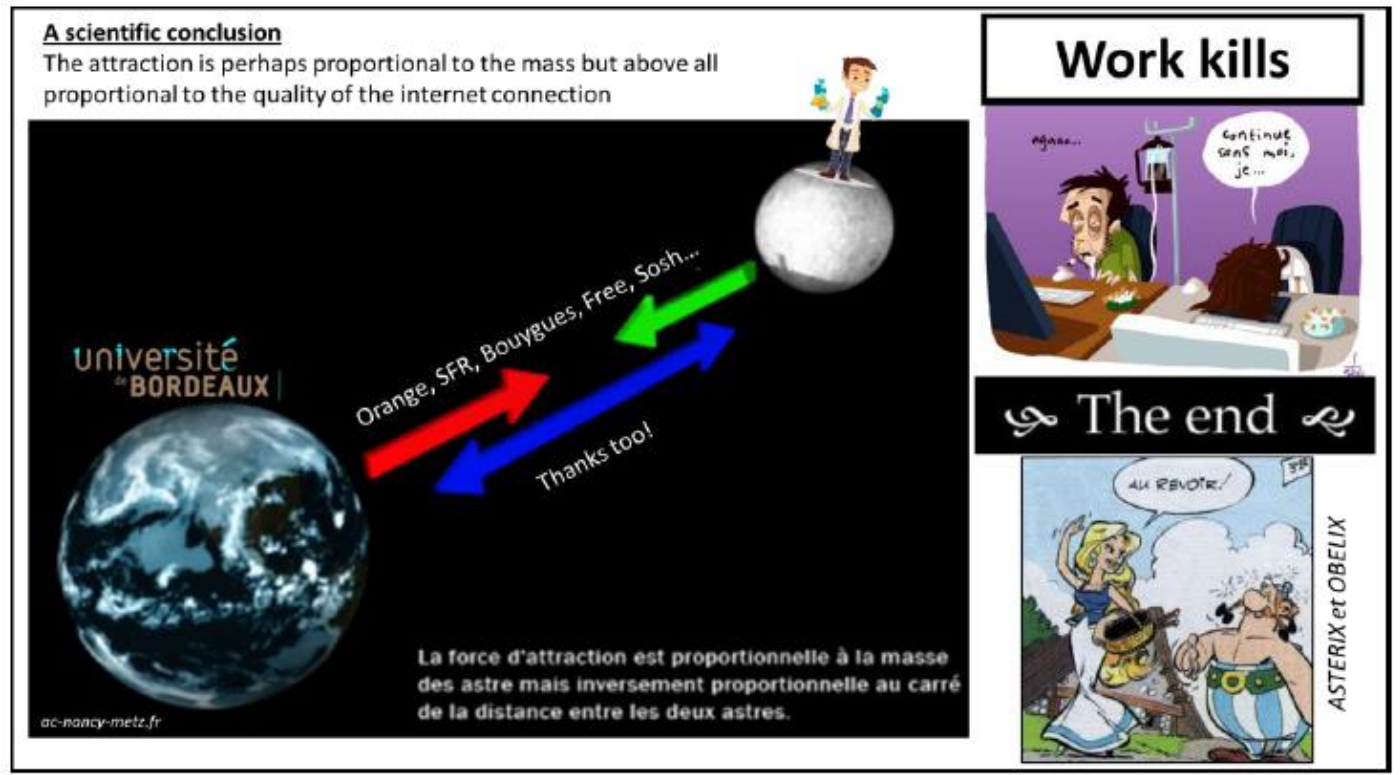

Appendix A. CoViBE 2 (practical work - session 2). How to use a fluorescence microscope? In response to the CoViBE success (episode 1), we agreed to design the episode 2 to address to the same students so that they could learn how to use a fluorescence microscope, a way to observe their immunocytofluorescence results and to apply their knowledges on fluorescence mechanism. This comic trip is composed of 14 frames showing the bench-top handling and materials needed, instructions, student questions (speech bubbles in black) and thinking (thinking bubbles in blue). Reading direction is from left to right. Humor is always present in this episode 2 and more essential because more technical knowledge is taught requiring more frames to avoid texts that are too long.

\section{Appendix B}

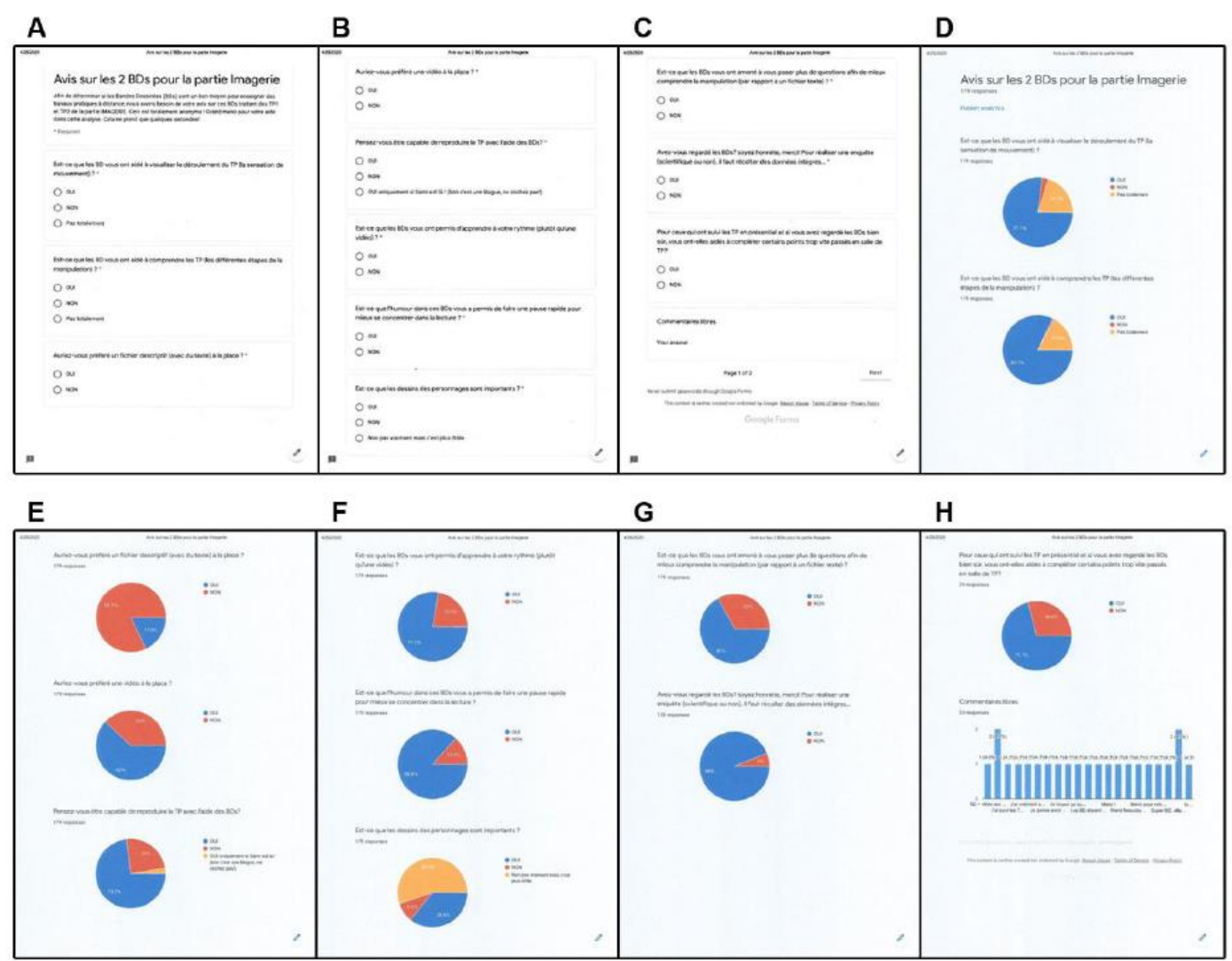


Appendix B. Original documents for the online survey. This online survey was created to ask French students about the CoViBE's impact on their learning of practical work. Many questions have been asked anonymously (A-C) and the answers from 179 students are presented using the pie chart expressed in percentage (D-H): 76 students performed the practical work face to face and 103 students who did not. We have suggested additional comments but we have not provided any relevant information from this part (bottom of $\mathrm{H}$ ). These documents are the originals and so, in French language (https://www.google.com/docs/about/).

\section{Appendix C}
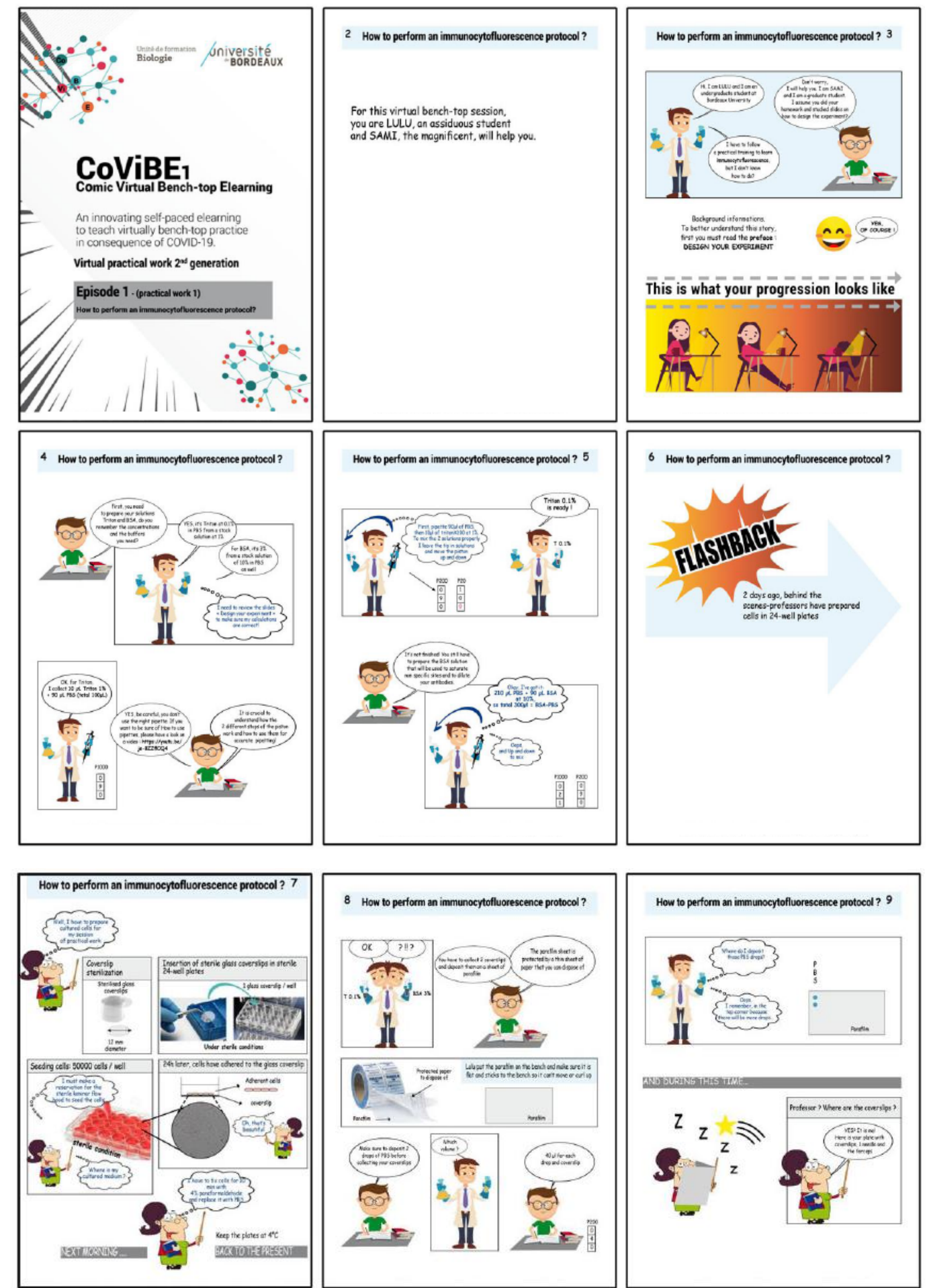

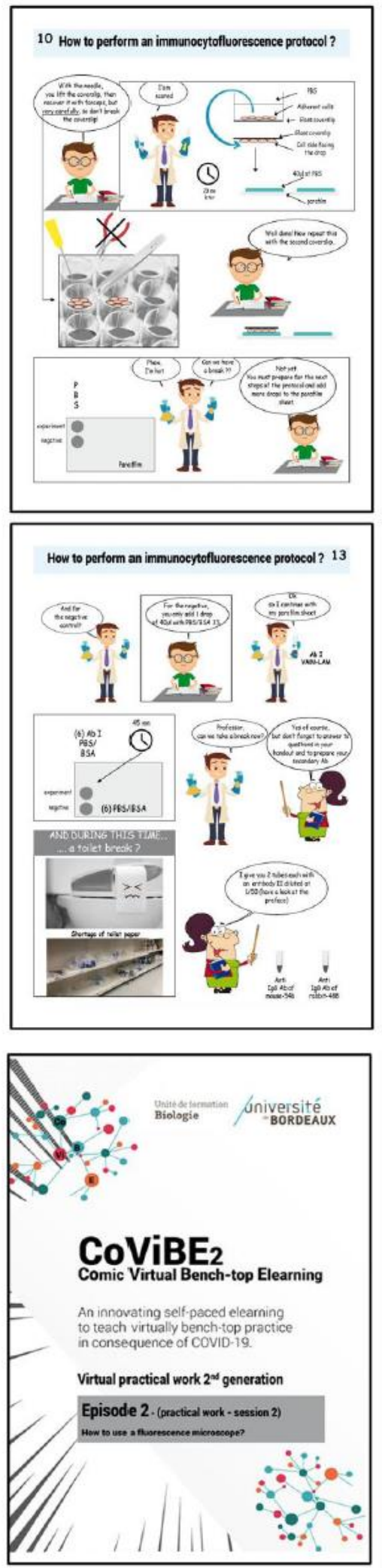
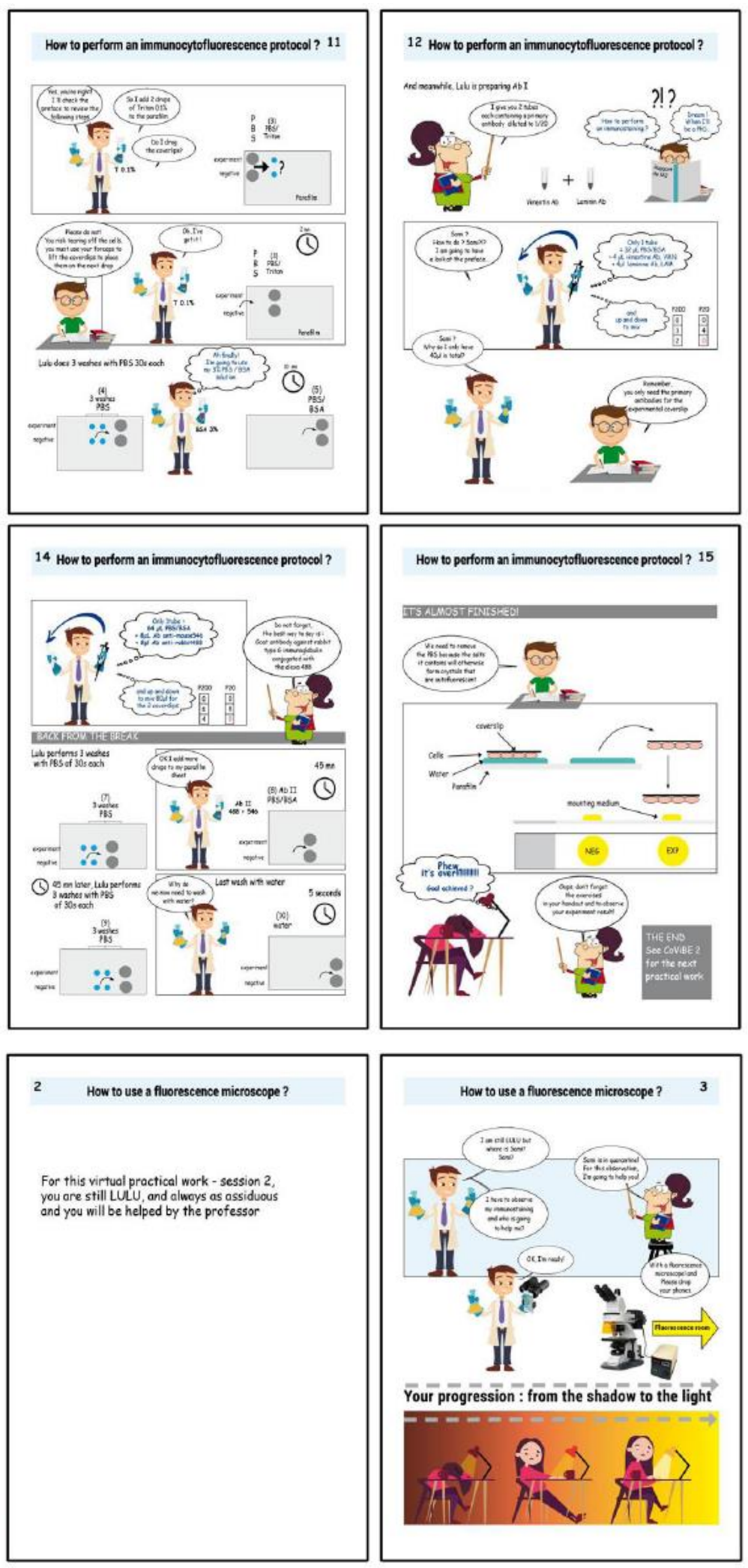

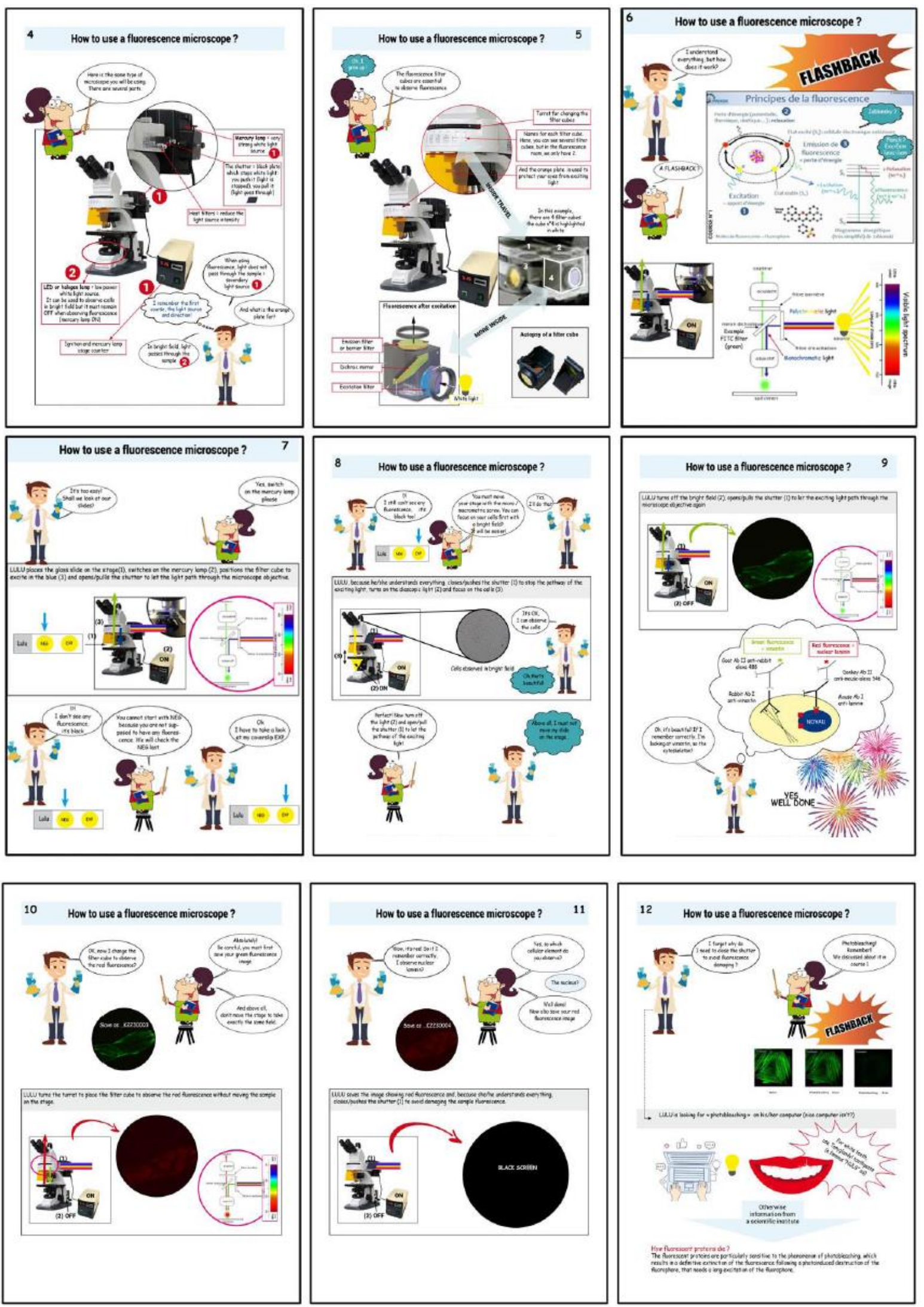

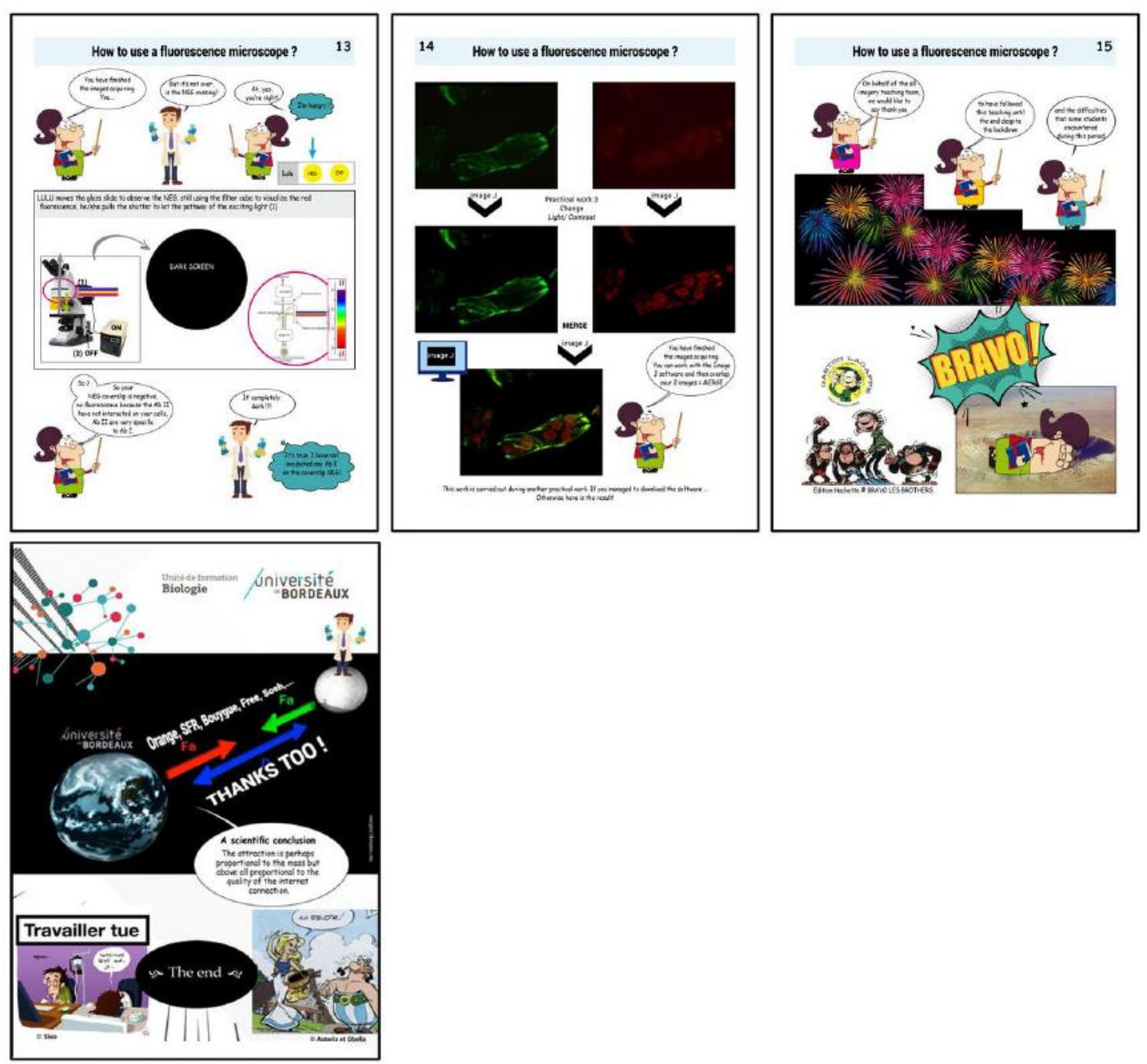

Appendix C. Second generation of CoViBE: CoViBE 1 (How to do an immunocytofluorescence protocol?) and CoViBE 2 (How to use a fluorescence microscopy?). For undergraduate students, this second generation of the CoViBE is more original and more didactic: episodes 1 and 2 are gathered to teach two sessions of practical work from the theory to practice. Reading direction is from left to right and from top to bottom. This document can be served as a book with 31 pages. All rights reserved and created by Opaline.com Agency (These pages could be available as a PDF file).

\section{Copyrights}

Copyright for this article is retained by the author(s), with first publication rights granted to the journal.

This is an open-access article distributed under the terms and conditions of the Creative Commons Attribution license (http://creativecommons.org/licenses/by/4.0/). 